\title{
Optimization of Diamond Nucleic Acid Dye for quantitative PCR
}

\author{
Alicia M. Haines ${ }^{1}$, Shanan S. Tobe ${ }^{1,2}$, and Adrian Linacre ${ }^{1}$ \\ ${ }^{1}$ School of Biological Sciences, Flinders University, Adelaide, Australia and ${ }^{2}$ Department of Chemistry and \\ Physics, Arcadia University, Glenside, PA
}

BioTechniques 61:183-189 (October 2016) doi 10.2144/000114458

Keywords: Diamond nucleic acid dye; quantitative PCR (qPCR); Real-time PCR; SYBR Green

Here, we evaluate Diamond Nucleic Acid Dye (DD) for use in quantitative PCR (qPCR) applications. Although DD is a commercially available stain for detection of DNA separated by gel electrophoresis, its use as a detection dye in qPCR has yet to be described. To determine if DD can be used in qPCR, we investigated its inhibitory effects on qPCR at concentrations ranging 0.1-2.5x. Serial dilution of DNA was used to determine the efficiency, sensitivity, and linearity of DD-generated qPCR data in comparison to other commonly used fluorescent dyes such as SYBR Green (SG), EvaGreen (EG), and BRYT Green (BG). DD was found to be comparable with other dyes for qPCR applications, with an $R^{2}$ value $>0.9$ and an efficiency of 0.83. Mitochondrial DNA (mtDNA) target signals were successfully produced by DD over a DNA dilution range of 28 ng$0.28 \mathrm{pg}$, demonstrating comparable sensitivity to the other dyes investigated. $\mathrm{C}_{\mathrm{q}}$ values obtained using DD were lower than those using EG by almost 7 cycles. We conclude that Diamond Nucleic Acid Dye is a cheaper, less toxic alternative for qPCR applications.

Fluorescent dyes have been used in quantitative PCR (qPCR) for many years (1). The most commonly used of these dye is the cyanine intercalating dye SYBR Green I (SG) (2). SG is known for its DNA binding sensitivity and is reported to have an 1000 -fold increase in fluorescence when bound to DNA $(3,4)$. Other fluorescent dyes that have been established for use in qPCR include EvaGreen (EG) (5), LCGreen (6), SYTO dyes (7), ResoLight (8), and BRYT Green (BG) (9), amongst others. One well-known issue with the use of SG in the laboratory is its mutagenic and toxic nature, as it can easily penetrate the cell membrane (10). SG is stated to cause mutations above the dosage of 33.3 $\mu \mathrm{g}$ per plate in the Ames Test. The toxicity of another commonly used dye, ethidium bromide (EtBr), is observed at 250-500 $\mu \mathrm{g}$ dosages per plate in the Ames Test.
Diamond Nucleic Acid Dye (DD) is an external groove binding dye shown to have a similar sensitivity as SG and a limit of detection of $0.5 \mathrm{ng}$ when detecting DNA in agarose gels (10). DD can penetrate the cell membrane, leading to interactions with genomic DNA (10); however, studies have shown that DD is less mutagenic and genotoxic when compared with $\mathrm{EtBr}$ (11). This reduction in toxicity may be due to the different binding mechanism of DD with DNA compared with other intercalating dyes, since DD does not bind between base pairs of DNA but instead binds externally (10). Currently, DD has not been evaluated for use in qPCR applications.

EG has been established for its use with $\mathrm{QPCR}$ and with high-resolution melt (HRM) curve analysis, as it has been shown to be stable in PCR (5). SG is known to inhibit PCR at high concen- trations and, with $25 \mathrm{ng}$ of DNA, was shown to inhibit the reaction at concentrations $>1 \times$. In comparison, EG still shows amplification at a concentration of 2.5x, indicating that EG inhibits PCR less than SG (12).

Here, we investigate the use of DD in GPCR and compare the effectiveness of $D D$ to the other fluorescent GPCR dyes: SG, EG, and BG. We determined the optimal concentration of DD within the reaction, the level of amplification inhibition, and the sensitivity and efficiency of the reaction. To determine how robust $D D$ is, various primers were chosen that generated different product lengths. As DD is a much cheaper dye than SG ( 5-fold cheaper) and is stated to be less toxic and mutagenic than $\mathrm{EtBr}$ (www.promega.com.au/resources/ pubhub/diamond-nucleic-acid-dyeis-a-safe-and-economical-alternativeto-ethidium-bromide/), DD presents a

\section{METHOD SUMMARY}

Application of Diamond Nucleic Acid Dye for the quantification of DNA using real-time PCR and a mitochondrial target sequence is presented. Comparisons are made with established fluorescent dyes, and the benefits of using the Diamond dye are detailed. 

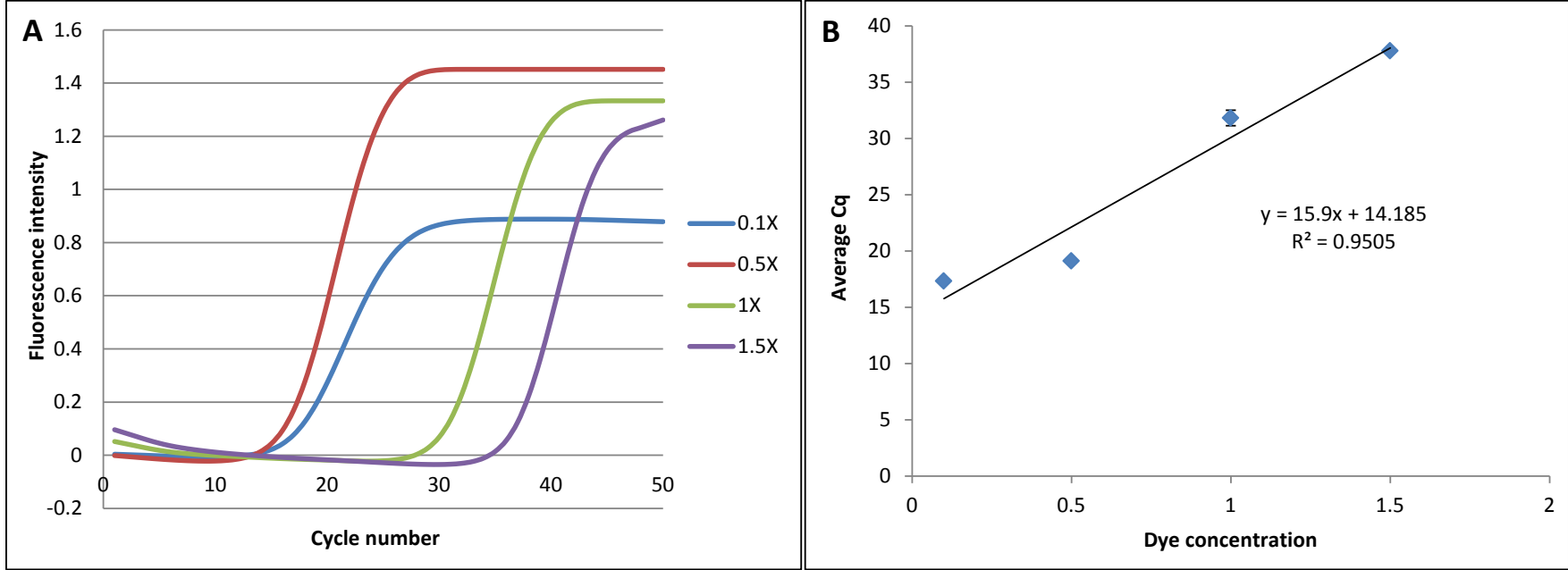

Figure 1. Effect of dye concentration on cycle number and level of inhibition of Diamond Nucleic Acid Dye (DD) on the reaction (A) Average cycling curve of normalized fluorescence intensity against cycle number with varying DD concentration $(0.1-1.5 \times)$. (B) The line of best fit for DD dye concentration agains average $\mathrm{C}_{\mathrm{q}}$ value with the threshold set at 0.12 ; error bars indicate the $95 \%$ confidence intervals. Complete inhibition was observed at concentrations $>1.5 \times$.

suitable alternative fluorescent dye for use in GPCR provided its sensitivity and efficiency are comparable to the dyes used currently.

\section{Materials and methods}

Optimization of fluorescent dye concentration for qPCR

Diamond Nucleic Acid Dye (DD) (Promega, Sydney, Australia) was prepared as a 20x solution in a buffer of $1 \times$ tris-acetate (TA) by a 1:500 dilution of the stock concentrate $(10,000 \times)$. The primer sequences and amplicon properties for this study are shown in Table 1 and described in
Reference 13. Fragment 1 primers were used to determine the inhibition effect of DD on PCR amplification. Five different reactions were prepared in quadruplicate; the quantity of DNA remained constant at $20 \mathrm{ng}$ in each reaction, but the final dye concentration varied $(0.1 \times$, $0.5 \times, 1 \times, 1.5 x, 2 \times, 2.5 x$ ) in a total reaction volume of $20 \mu \mathrm{L}$. Amplifications were performed in a 72 Rotor-Disc in a RotorGene Q (Qiagen, Qiagen, Chadstone Centre, Australia. The channels selected for fluorescence detection were green (excitation $470 \pm 10 \mathrm{~nm}$, emission 510 $\pm 5 \mathrm{~nm})$ and a modified channel labeled "diamond" (excitation $470 \pm 10 \mathrm{~nm}$,

Table 1: qPCR primer sequences used in this study and properties of the resulting amplicons.

\begin{tabular}{|c|c|c|c|c|}
\hline & Primer sets & $5^{\prime} \longrightarrow{ }^{\prime}$ & Amplicon length (bp) & $\operatorname{Tm}\left({ }^{\circ} \mathbf{C}\right)$ \\
\hline 1 & Fragment 1 & $\begin{array}{l}\text { F-GACCAATGATATGAAAAACCATCGTTGT } \\
\text { R-CAAGCATACTCCTAGTAAGGATCCG }\end{array}$ & 170 & $\begin{array}{l}68.8 \\
64.67\end{array}$ \\
\hline 2 & Fragment 2 & $\begin{array}{l}\text { F-TGAGGACAAATATCATTYTGAGGRGC } \\
\text { R-ATCGGAATGGGAGGTGATTCCTAGG }\end{array}$ & 246 & $\begin{array}{l}67.6 \\
71.3\end{array}$ \\
\hline
\end{tabular}

Primer sets 1 and 2 targeted the end of the mitochondrial genes for tRNA-Glu and cytochrome b, respectively. These primer sets, which were used to test the suitability of Diamond Nucleic Acid Dye (DD) relative to other qPCR dyes, were selected based on the product size and also to ensure that there was a minimal chance of contamination from the operator between the different dyes tested. This was accomplished using non-human (Primer set 1) and human-specific primers (Primer set 2). Primer design published in Tobe and Linacre (13).

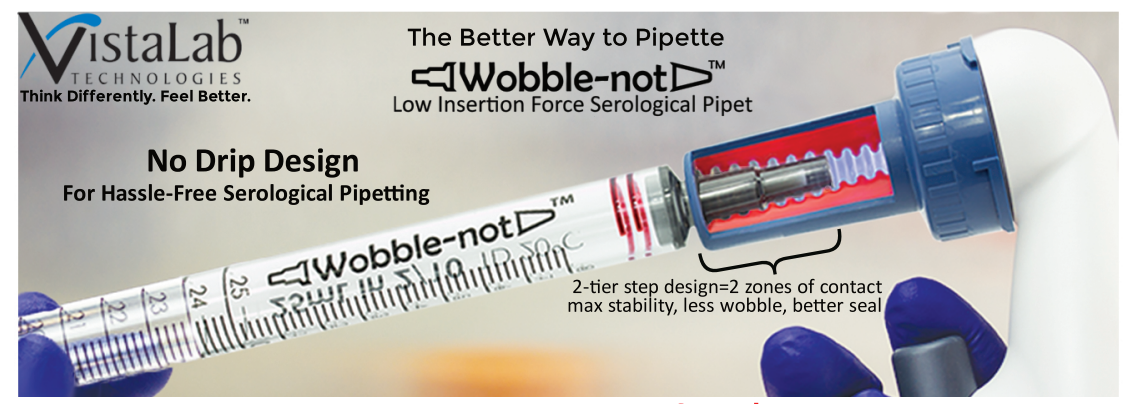

Available through distributors For more information go to www.vistalab.com/wobble-not
Free Samples! Submit request online at www.vistalab.com/wobble-not/\#get-free-sample-pack emission $557 \pm 5 \mathrm{~nm}$ ) to account for the differences in the excitation $(494 \mathrm{~nm})$ and emission (558 nm) of DD compared with the excitation (495 nm) and emission (520 $\mathrm{nm}$ ) of SG. The PCR program began with an initial hold at $95^{\circ} \mathrm{C}$ for $2 \mathrm{~min}$, then 50 cycles at $95^{\circ} \mathrm{C}$ for $10 \mathrm{~s}, 60^{\circ} \mathrm{C}$ for $15 \mathrm{~s}$, and $72^{\circ} \mathrm{C}$ for $20 \mathrm{~s}$. This was followed by a melt from $72^{\circ} \mathrm{C}$ to $95^{\circ} \mathrm{C}$ in $1^{\circ} \mathrm{C}$ increments.

The median $\mathrm{C}_{\mathrm{q}}$ value was calculated for each dye concentration, and the slope of the trendline generated by plotting the median $\mathrm{C}_{\mathrm{q}}$ value against the dye concentration was used as an indicator of the degree of amplification inhibition.

Determination of DD efficiency and sensitivity compared with SYBR Green, EvaGreen, and BRYT Green A series of dilutions was prepared to determine the efficiency of DD, EG, and $B G$ in $\mathrm{PPCR}$, and to compare these to SG. Amplifications were performed using Fragment 2 primers, which produce a 246-bp amplicon (Table 1). Five 10-fold serial dilutions to a final dilution of $1 / 10^{5}$ were prepared from neat DNA (whole genomic DNA from a buccal swab prepared by a solid phase extraction) quantified by a Qubit dsDNA HS Assay at $28.4 \mathrm{ng} / \mu \mathrm{L}$ (Thermo Fisher Scientific, Scoresby, Australia). A no-template control was prepared for quality control to determine if any contamination was present in any of the reagents.

Based on the results of part 1 of this study investigating optimal dye concentration, DD was used at a final 


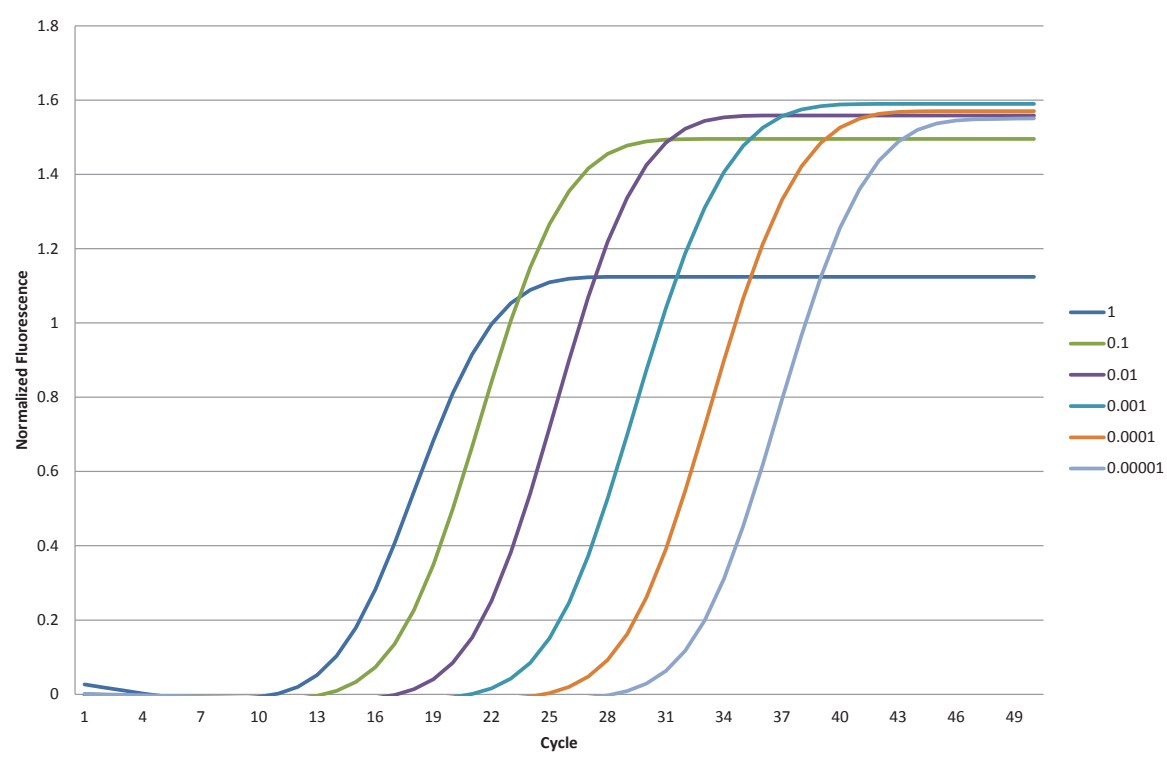

Figure 2. Average qPCR cycling with a $\mathbf{5}$-dilution series over 50 cycles using $\mathbf{0 . 5 \times}$ Diamond Nucleic Acid Dye (DD). Detection was done using the diamond channel, with 1 being the neat DNA concentration at $28.4 \mathrm{ng} / \mu \mathrm{L}$, followed by $1 / 10$ serial dilutions. Reactions were done in quadruplicate.

concentration of $0.5 x$. The DD reactions consisted of $10 \mu \mathrm{L}$ KAPA Taq ReadyMix 2x (GeneWorks Pty Ltd, Thebarton, Australia), $0.5 \mu \mathrm{L}$ of each primer pair $(10 \mu \mathrm{M} / \mu \mathrm{L}), 0.5 \mu \mathrm{L} 20 \times \mathrm{DD}, 1 \mu \mathrm{L} \mathrm{DNA}$ solution, and $8 \mu \mathrm{L}$ TA buffer, in a total reaction volume of $20 \mu \mathrm{L}$. The SG reactions consisted of $10 \mu \mathrm{L} \mathrm{KAPA}$ SYBR FAST qPCR Master Mix 2× (Kapa Biosystems), $0.5 \mu \mathrm{L}$ of each primer pair, 1 $\mu \mathrm{L}$ DNA solution, and $8.5 \mu \mathrm{L}$ TA buffer, in a total reaction volume of $20 \mu \mathrm{L}$. The BG reaction consisted of $10 \mu \mathrm{L}$ GoTaq qPCR Master Mix 2× (Promega), $0.5 \mu \mathrm{L}$ of each primer pair, $1 \mu \mathrm{L}$ DNA solution, and 8.5 $\mu \mathrm{L}$ TA buffer, in a total reaction volume of $20 \mu \mathrm{L}$. The EG reaction consisted of $10 \mu \mathrm{L}$ KAPA Taq ReadyMix $2 \times, 0.5 \mu \mathrm{L}$ of each primer pair, $1 \mu \mathrm{L} E \mathrm{EG}$ at $20 \times, 1 \times$ concentration as suggested by the manufacturer's protocol (Jomar Life Research, Scoresby, Australia), $1 \mu \mathrm{L}$ DNA solution, and $7.5 \mu \mathrm{L}$ TA buffer, in a total reaction volume of $20 \mu \mathrm{L}$. A negative control (NTC) was prepared for each of the dyes tested to determine if any contamination was present; the reactions were prepared as above with an extra $1 \mu \mathrm{L} 1 \times$ TA buffer added instead of DNA.

All reactions were performed in quadruplicate. Amplifications were performed on a 72 Rotor-Disc in a Rotor-Gene Q. The channels selected for fluorescence detection were green and diamond (see above). The PCR cycle began with an initial hold at $95^{\circ} \mathrm{C}$ for 2 min, then 50 cycles at $95^{\circ} \mathrm{C}$ for $10 \mathrm{~s}$, $60^{\circ} \mathrm{C}$ for $15 \mathrm{~s}$, and $72^{\circ} \mathrm{C}$ for $20 \mathrm{~s}$. This was followed by a melt from $72^{\circ} \mathrm{C}$ to $95^{\circ} \mathrm{C}$ in $1^{\circ} \mathrm{C}$ increments.

The lower limit of sensitivity of the reaction was determined by preparing a $1 / 10^{6}$ dilution to determine if a signal from any of the dyes could be detected. This was performed in quadruplicate.

\section{Results and discussion}

We first assessed the impact of DD concentration on PCR amplification. Our data showed that the optimal concentration of DD for qPCR was $0.5 \times$ (Figure

Table 2: Average $C_{q}$ values for dilution series of each fluorescent dye.

\begin{tabular}{|c|c|c|c|c|}
\hline Dilution & $\begin{array}{l}\text { Diamond Nucleic } \\
\text { Acid Dye (DD) }\end{array}$ & SYBR Green I (SG) & EvaGreen (EG) & BRYT Green (BG) \\
\hline 1 & $13.82(0.02)$ & $12.33(0.03)$ & $17.45(0.03)$ & $14.02(0.03)$ \\
\hline $1 / 10$ & $15.53(0.02)$ & $15.26(0.05)$ & $20.97(0.07)$ & $17.40(0.07)$ \\
\hline $1 / 100$ & $19.37(0.20)$ & $19.33(0.12)$ & $25.48(0.11)$ & $21.72(0.08)$ \\
\hline $1 / 10^{3}$ & $23.17(0.08)$ & $22.99(0.08)$ & $29.84(0.17)$ & $25.68(0.05)$ \\
\hline $1 / 10^{4}$ & $27.03(0.71)$ & $26.28(0.20)$ & $34.50(0.42)$ & $29.24(0.12)$ \\
\hline $1 / 10^{5}$ & $32.93(1.47)$ & $31.93(0.26)$ & $39.92(0.41)$ & $34.51(0.48)$ \\
\hline
\end{tabular}

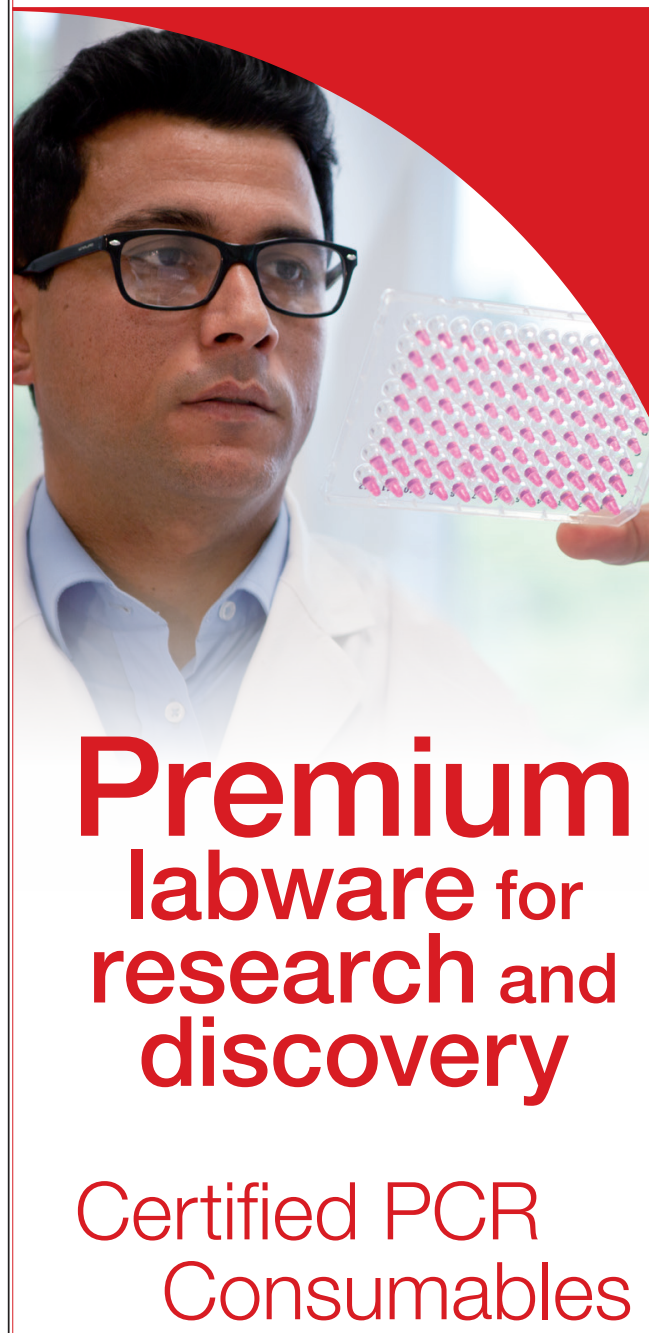

- Full Range of Products

- Options for qPCR

- Highest Purity Standards
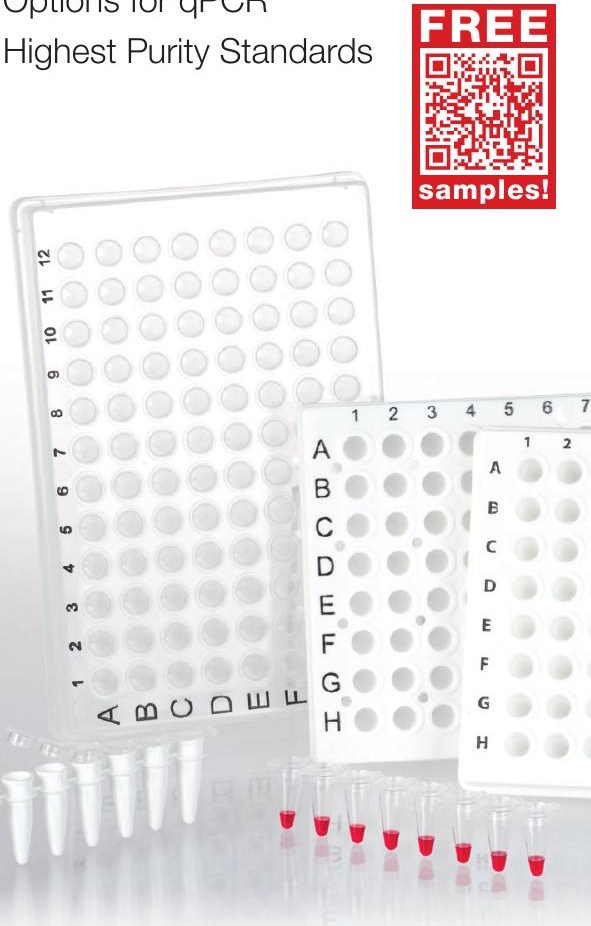

www.sarstedt.com 
1). The slope of the trendline (Figure 1B) indicates the degree of amplification inhibition (15.9) as the concentration of the DD increases. Complete inhibition occurred at concentrations $>1.5 x$ (data not shown), and partial inhibition occurred at $1.5 \times$ (2 of 4 replicates had an amplification product).

A previous study (12) showed that at lower DNA quantities (25 ng), SG can inhibit the reaction when concentrations are $>0.5 \times$. This is in contrast to DD, which showed inhibition at concentrations $>1.5 \times$. In the same study, EG showed no inhibition of qPCR at concentrations $>2 \times$, with DNA amounts ranging 25-100 ng (12), indicating EG has less of an inhibitory effect on qPCR when compared with DD.

Average $C_{q}$ values for DD were 0.04-1.49 cycles higher than SG (Table 2); a higher $\mathrm{C}_{\mathrm{q}}$ value indicates a lower initial copy number for the target amplification product. It should be noted that DD was compared with the SG kit (KAPA SYBR FAST qPCR Kit), which has an engineered Taq polymerase that is more resistant to the inhibitory effects of $S G$ within the reaction, as stated by the manufacturer. We expect that with a similar manufacturing process, DD would likely show improved $\mathrm{C}_{\mathrm{q}}$ values from those determined in this study. In comparison to EG, DD has lower $\mathrm{C}_{\mathrm{a}}$ values, ranging 3.63-7.47 fewer cycles. When comparing DD to BG, the $\mathrm{C}_{\mathrm{a}}$ values for DD are on average 0.20-2.51 cycles lower than BG.

Total human genomic DNA was quantified using the Qubit dsDNA HS Assay (28.4 $\mathrm{ng} / \mu \mathrm{L}$ ) and was used as an approximation of the total amount of DNA present in the sample. The manufacturer states the assay is able to accurately detect between $0.2 \mathrm{pg} /$ $\mu \mathrm{L}$ and $100 \mathrm{ng} / \mu \mathrm{L}$ DNA. As the primers used in these reactions are for the mitochondrial genome, the detection limit would be expected to be lower than for primers used to target nuclear DNA. Due to the multi-copy nature of mitochondrial DNA (mtDNA) within a single mitochondrion and the variation in the number of mitochondria per cell, it is not possible to determine the exact number of mitochondrial genomes per cell; however an average of 500 per cell has been suggested (14). Based on this average value, the neat sample (28.4

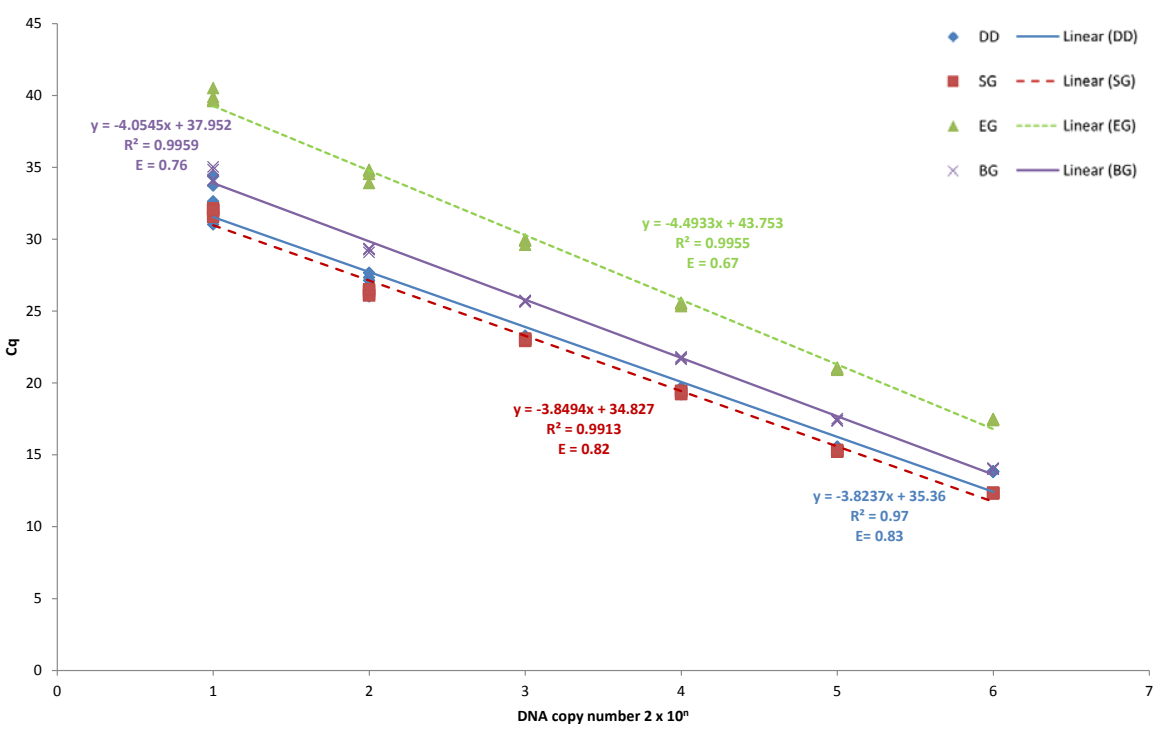

Figure 3. Standard curves of DNA concentration against $C_{q}$ values for the different fluorescent dyes. SYBR Green (SG), BRYT Green (BG), and EvaGreen (EG) were analyzed through the green channel, and Diamond Nucleic Acid Dye (DD) was analyzed through the diamond channel. The efficiency of the reaction and the $R^{2}$ values indicating the linearity of the dyes' fluorescent signals are also shown.

$\mathrm{ng} / \mu \mathrm{L})$ contains $\sim 2.1$ million copies of $\mathrm{mtDNA} / \mu \mathrm{L}$, and the lowest dilution $\left(1 / 10^{6}\right)$ contains $\sim 2$ copies of $\mathrm{mtDNA} / \mu \mathrm{L}$. This is comparable to the sensitivity claimed for SG.
Our data showed that DD exhibited a curve shape that is seen with other commonly used dyes for qPCR, such as SG, EG, and BG (Figure 2), demonstrating its suitability for use in qPCR.

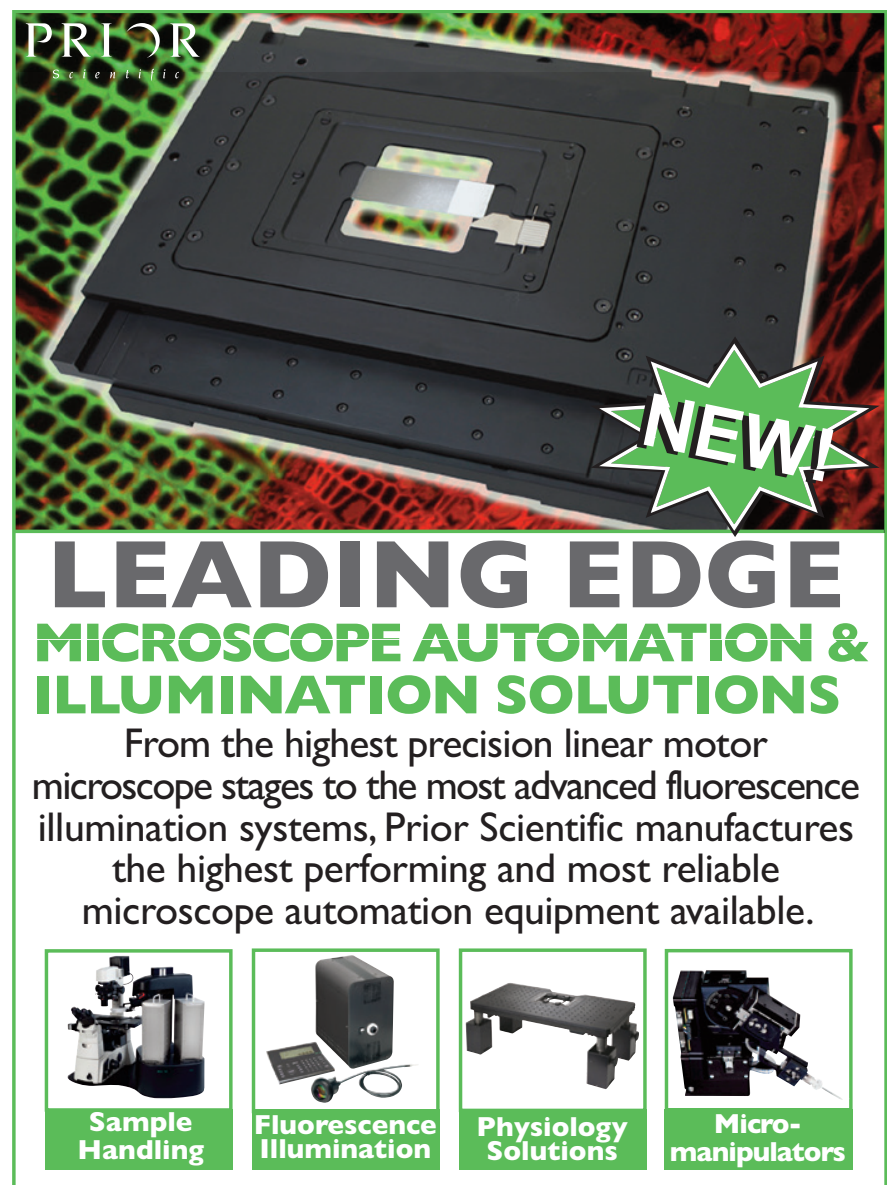


A

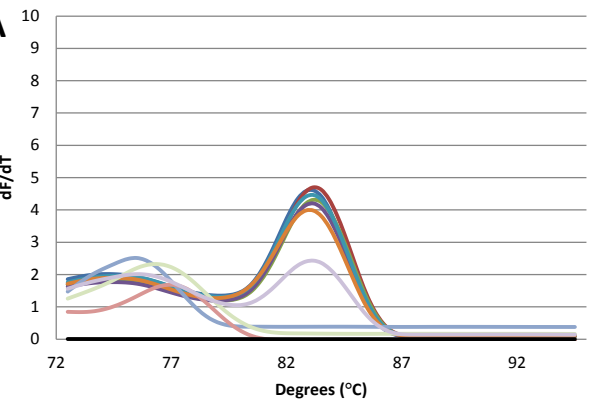

B

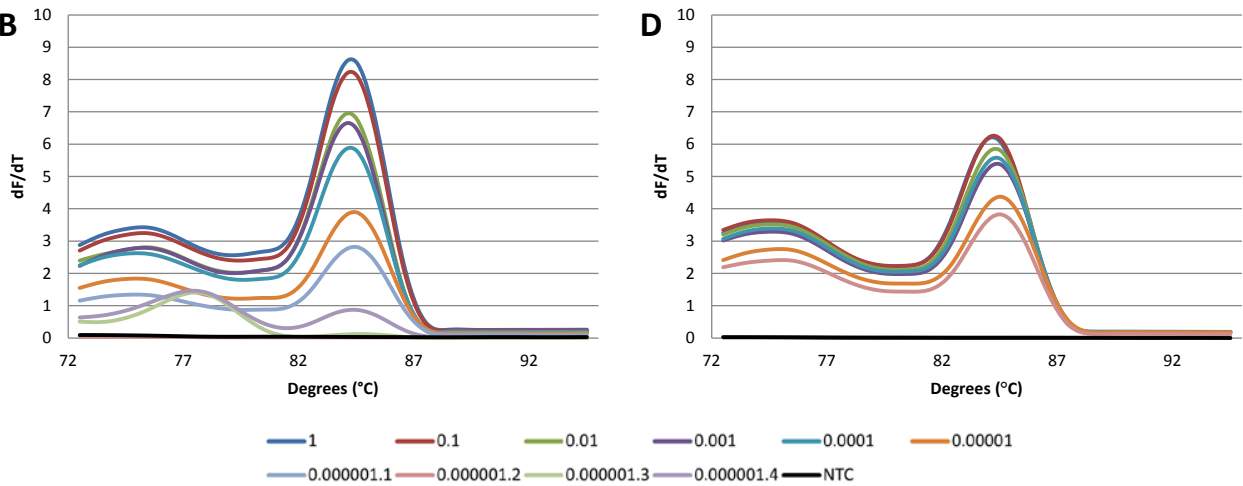

Figure 4. Average melt curve of serial dilutions of DNA (A) SYBR Green (SG); (B) EvaGreen (EG); (C) Diamond Nucleic Acid Dye (DD); and (D) BRYT Green (BG). SG, EG, and BG were analyzed through the green channel, and DD was analyzed through the diamond channel. The value for the neat DNA at $28.4 \mathrm{ng} / \mathrm{\mu L}$ is 1 , followed by the $1 / 10$ serial dilutions. All of the replicates for the $1 / 10^{6}$ dilution are shown in order to illustrate their variability. NTC $=$ no-template control.

\section{DETECT CRISPR GENE EDITLIG EVEITS Using Agarose Gels}

ACCUCLEAVE ${ }^{\text {TM }}$ T7 KIT

- T7 based enzyme kit for mutation frequency detection of CRISPR events.

CRISPR 2 CONTROL DNA KIT

- Contains 2 Control DNA fragments - intact and -2 deletion fragment.

\section{CRISPR 15 CONTROL DNA KIT}

- Contains 15 Control DNA fragments - intact, \pm 1 , $\pm 2, \pm 10$ indels and 8 point mutations.

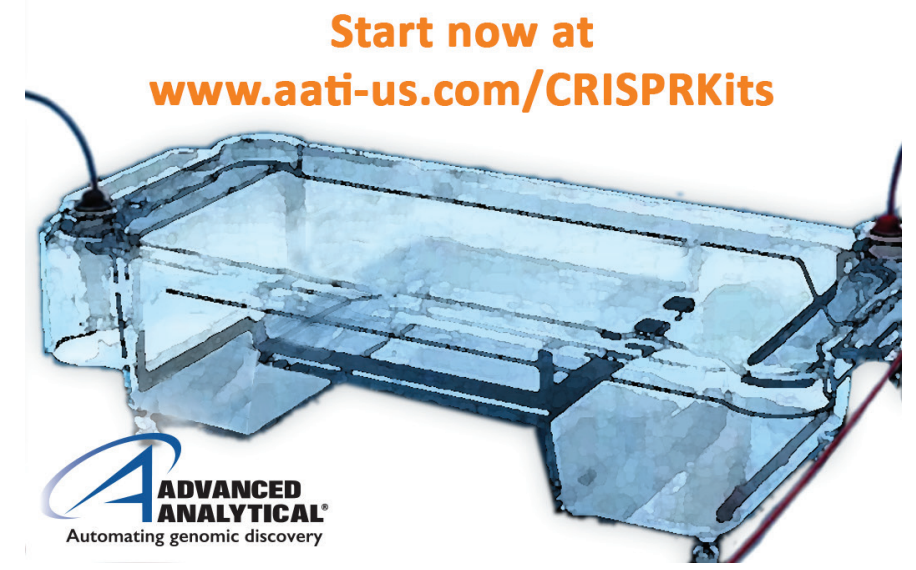

The linearity $\left(R^{2}\right)$ of the standard curves was $>0.97$ for all dyes (Figure 3). BG had the highest $R^{2}$ value (0.996) and DD had the lowest value (0.970). Based on the values generated from the standard curve in relation to the slope (15), DD had the highest reaction efficiency at 0.83 and $E G$ had the lowest at 0.67 (Figure 3). Combining all of the aspects of qPCR (15), it can be seen that DD is comparable with other currently commercially available dyes.

At genomic DNA concentrations less than the $1 / 10^{5}$ dilution, the dyes were not capable of generating a reproducible signal, and at a $1 / 10^{6}$ dilution, the samples failed to amplify. Some replicates that did not produce an amplification signal produced a broad melt peak at $\sim 75-77^{\circ} \mathrm{C}$ (Figure 4). One of the 4 replicates of the $1 / 10^{6}$ dilution SG sample (Figure 4A) produced the target melt peak. The other 3 replicates had a broad peak ranging $\sim 75-77^{\circ} \mathrm{C}$, and these peaks were 5 -fold smaller than the peak seen for DD (Figure 4C). Similarly, for BG (Figure 4D), 1 of 4 replicates for the $1 / 10^{6}$ dilution produced the target melt product; the other 3 replicates and the NTC produced no products. For EG, the 1 of 4 replicates for the $1 / 10^{6}$ dilution produced the target melt peak, along with a broad peak at $77^{\circ} \mathrm{C}$; another of the replicates produced only a broad peak at $77^{\circ} \mathrm{C}$; and the remaining 2 replicates and the NTC produced no products (Figure 4B).

For $\mathrm{DD}$, there were no amplification products in the $1 / 10^{6}$ dilution sample and the NTC samples (Figure 4C). The observed broad minor melt peaks are $\sim 77^{\circ} \mathrm{C}$, which would likely correspond to the expected melting point of the primer-dimer. All of the other DNA dilutions for DD had peaks at $\sim 85^{\circ} \mathrm{C}$. The results from the $1 / 10^{6}$ dilution may be due to differences in the binding mechanism of DD in compared to the other dyes typically used. DD is an external groove binding dye, which means the DNA does not need to be double-stranded for the dye to bind. The molecular structure of DD is proprietary, which limits any further comment on mechanism. In comparison, $S G$, which intercalates between the base pairs of DNA and has electrostatic interactions, only binds double-stranded DNA (dsDNA) (3). This would be a plausible explanation as to why DD produces a signal in the NTC and in dilutions that are too low for detectable amplification.

A further study was conducted to determine if $D D$ binds to single-stranded DNA (ssDNA), but there were no ssDNA 
amplification products (data not shown); therefore, this was not the cause of the variability in DD at the lowest dilutions (Figure 3). Furthermore, the disassociation of DD from ssDNA occurs at a relatively low temperature of $\sim 73^{\circ} \mathrm{C}$ (data not shown), which is $\sim 4$ degrees lower than the temperature at which the primer dimer was observed in the reactions $\left(77^{\circ} \mathrm{C}\right)$ (Figure 4). The binding of DD to ssDNA is therefore not likely to be an issue for normal $\mathrm{qPCR}$ reactions.

This is the first study to examine the use of DD, which to date has only been used for staining agarose gels, for qPCR. The inhibitory effect DD has on PCR was investigated, and DD was found to completely inhibit the reaction at concentrations $>1.5 x$. The efficiency, linearity, and sensitivity of the reaction were also investigated using serial dilutions of DNA. DD allowed detection of as little as $0.28 \mathrm{pg}$ of DNA ( 20 copies of $m$ tDNA target). This sensitivity is comparable to $S G, E G$, and BG, which are currently used for qPCR. DD is a suitable, and cheaper (by approximately 5 fold), alternative to the dyes currently used for qPCR detection.

\section{Author contributions}

A.M.H., S.S.T., and A.L. conceived the idea for the study. A.M.H. performed all laboratory work. A.M.H., S.S.T., and A.L. analyzed the data and drafted the manuscript. All authors approved of the final manuscript prior to submission.

\section{Acknowledgments}

Funding was provided by Forensic Science South Australia.

\section{Competing interests}

The authors declare no competing interests

\section{References}

1. Klein, D. 2002. Quantification using real-time PCR technology: applications and limitations. Trends Mol. Med. 8:257-260.

2. Monis, P.T., S. Giglio, and C.P. Saint. 2005. Comparison of SYTO9 and SYBR Green I for real-time polymerase chain reaction and investigation of the effect of dye concentration on amplification and DNA melting curve analysis. Anal. Biochem. 340:24-34.

3. Dragan, A.I., R. Pavlovic, J.B. McGivney, J.R. Casas-Finet, E.S. Bishop, R.J. Strouse, M.A. Schenerman, and C.D. Geddes. 2012. SYBR Green I: Fluorescence Properties and Interaction with DNA. J. Fluoresc. 22:11891199.
4. Cosa, G., K.S. Focsaneanu, J.R.N. McLean, J.P. McNamee, and J.C. Scaiano. 2001. Photophysical Properties of Fluorescent DNA-dyes Bound to Single- and Doublestranded DNA in Aqueous Buffered Solution. Photochem. Photobiol. 73:585-599.

5. Mao, F., W.-Y. Leung, and X. Xin. 2007. Characterization of EvaGreen and the implication of its physicochemical properties for qPCR applications. BMC Biotechnol. 7:76.

6. Wittwer, C.T., G.H. Reed, C.N. Gundry, J.G. Vandersteen, and R.J. Pryor. 2003. HighResolution Genotyping by Amplicon Melting Analysis Using LCGreen. Clin. Chem. 49:853860.

7. Eischeid, A.C. 2011. SYTO dyes and EvaGreen outperform SYBR Green in real-time PCR. BMC Res. Notes 4:263.

8. Rouleau, E., C. Lefol, V. Bourdon, F. Coulet, T. Noguchi, F. Soubrier, I. Bièche, S. Olschwang, et al. 2009. Quantitative PCR high-resolution melting (qPCR-HRM) curve analysis, a new approach to simultaneously screen point mutations and large rearrangements: application to MLH1 germline mutations in Lynch syndrome. Hum. Mutat. 30:867-875.

9. Imperiali, C., P. Alía-Ramos, and A. PadróMiquel. 2015. Rapid detection of HLA-B ${ }^{\star} 51$ by real-time polymerase chain reaction and highresolution melting analysis. Tissue Antigens 86:139-142.

10. Haines, A.M., S.S. Tobe, H.J. Kobus, and A. Linacre. 2015. Properties of nucleic acid staining dyes used in gel electrophoresis. Electrophoresis 36:941-944.

11. Singer, V.L., T.E. Lawlor, and S. Yue. 1999. Comparison of SYBR Green I nucleic acid gel stain mutagenicity and ethidium bromide mutagenicity in the Salmonella/mammalian microsome reverse mutation assay (Ames test). Mutat Res. 439:37-47.

12. Radvanszky, J., M. Surovy, E. Nagyova, G. Minarik, and L. Kadasi. 2015. Comparison of different DNA binding fluorescent dyes for applications of high-resolution melting analysis. Clin. Biochem. 48:609-616.

13. Tobe, S.S. and A.M.T. Linacre. 2008. A multiplex assay to identify 18 European mammal species from mixtures using the mitochondrial cytochrome b gene. Electrophoresis 29:340-347

14. Satoh, M. and T. Kuroiwa. 1991. Organization of multiple nucleoids and DNA molecules in mitochondria of a human cell. Exp. Cell Res. 196:137-140.

15. Bustin, S.A., V. Benes, J.A. Garson, J. Hellemans, J. Huggett, M. Kubista, R. Mueller, T. Nolan, et al. 2009. The MIQE Guidelines: Minimum Information for Publication of Quantitative Real-Time PCR Experiments. Clin. Chem. 55:611-622.

Received 26 April 2016; accepted 19 July 2016.

Address correspondence to Alicia M. Haines, Flinders University GPO Box 2100, School of Biological Sciences, Adelaide, SA, 5001, Australia. Email: alicia.haines@flinders.edu.au

To purchase reprints of this article, contact: biotechniques@fosterprinting.com

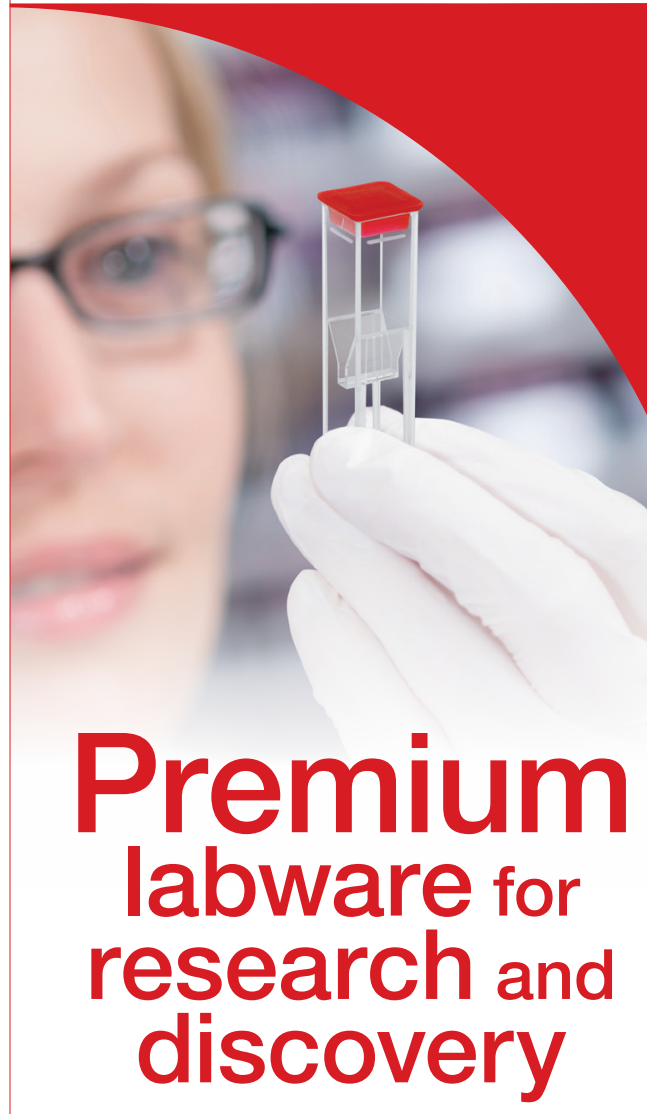

\section{UV-transparent Cuvettes}

- For measurements in the UV range below $300 \mathrm{~nm}$

- Economical and hygienic alternative to quartz cuvettes

- Minimal UV absorption for DNA, RNA, and protein quantification

- Certified DNA/RNase/protein-free
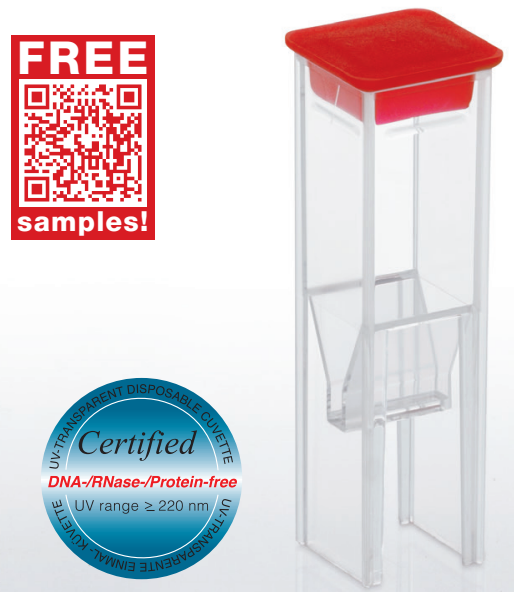

www.sarstedt.com 